\title{
Revitalisasi Posyandu Lansia di Desa Sumbertebu Kecamatan Bangsal Kabupaten Mojokerto
}

\author{
Revitalizing Elderly Posyandu in Sumbertebu Village, Bangsal District, Mojokerto Regency
}

Nurul Mawaddah*
Yudha Laga Hadi Kusuma
Mujiadi
Siti Rachmah
Anndy Prastya
Arief Fardiansyah
Department of Nursery, Sekolah
Tinggi Ilmu Kesehatan
Majapahit, Mojokerto, East Java,
Indonesia
*email:
mawaddah.ners@gmail.com
Kata Kunci
Lansia
Posyandu Lansia
Revitalisasi
Keywords:
Elderly
Elderly Posyandu
Revitalization
Accepted: November 2019
Published: December 2019

\begin{abstract}
Abstrak
Pelaksanaan posyandu lansia yang tidak optimal dan kurangnya pemahaman lansia tentang posyandu lansia menyebabkan kurangnya partisipasi dan pemanfaatan layanan oleh lansia. Kegiatan pengabdian masyarakat ini dilakukan di Posyandu Lansia Desa Sumbertebu dengan tujuan untuk meningkatkan keterampilan kader posyandu serta meningkatkan partisipasi lansia datang ke posyandu. Kegiatan revitalisasi meliputi kegiatan pelatihan kader, pembuatan media promosi kesehatan, sosialisasi pemanfaatan posyandu lansia melalui kunjungan ke rumah lansia, pendampingan pelaksanaan posyandu lansia, serta melaksanakan kegiatan pengembangan posyandu berupa senam lansia (bidang olah raga dan terapi kelompok (bidang pendidikan). Hasil kegiatan pengabdian kepada masyarakat ini meliputi meningkatnya keterampilan kader dalam pelaksanaan posyandu serta meningkatnya jumlah kunjungan lansia datang ke posyandu. Mengoptimalkan kegiatan pelayanan utama di posyandu serta kegiatan pengembangan mampu meningkatkan motivasi lansia datang keposyandu lansia.
\end{abstract}

\begin{abstract}
The implementation of posyandu for the elderly is not optimal and the lack of understanding of the elderly about the posyandu for the elderly causes a lack of participation and utilization of services by the elderly. This community service activity is carried out at the Posyandu Elderly in Sumbertebu Village with the aim to improve the skills of posyandu cadres and increase the participation of the elderly coming to the Posyandu. Revitalization activities include cadre training activities, making health promotion media, socializing the use of elderly posyandu through visits to elderly homes, assisting the implementation of elderly posyandu, and carrying out development activities in the form of elderly gymnastics (sports and group therapy (education). the results of this community service include increasing cadre skills in implementing posyandu and increasing the number of elderly visits to posyandu, optimizing the main service activities in posyandu and development activities capable of increasing the motivation of elderly people to come to the elderly posyandu.
\end{abstract} Open Access article under the CC-BY-SA License (http://creativecommons.org/licenses/by-sa/4.0/). DOI: https://doi.org/10.33084/ pengabdianmu.v5i1.963.

\section{PENDAHULUAN}

Keberhasilan pembangunan yang telah dilaksanakan, terutama dalam bidang kesehatan dan kesejahteraan sosial berdampak pada meningkatnya angka rata-rata usia harapan hidup penduduk (Braveman \& Gottlieb, 2014). Meningkatnya umur harapan hidup adalah salah satu indikator utama tingkat kesehatan masyarakat.
Semakin tinggijumlah lansia, maka semakin baik tingkat kesehatan masyarakatnya (Partini, 2011).

Berdasarkan data Statistik penduduk lanjut usia pada tahun 2018, persentase penduduk lansia indonesia mencapai 9,27\% atau sekitar 24,49 juta orang. Kondisi ini menunjukkan bahwa Indonesia sedang bertransisi menuju ke arah struktur penduduk tua (aging population) karena persentase penduduk berusia 60 tahun mencapai 
diatas 7\% dari keseluruhan penduduk. Jumlah ini akan semakin berarti jika kelompok lanjut usia bisa mandiri, berkualitas, tidak menjadi beban masyarakat serta dapat berperan dalam pembangunan nasional (Heryanah, 2015).

Peningkatan jumlah lansia tersebut selain menjadi salah satu indikator keberhasilan pembangunan, juga menjadi tantangan dalam pembangunan kesehatan untuk mempertahankan kesehatan lanjut usia tetap mandiri. Karena banyaknya permasalahan kesehatan yang dialami pada usia lanjut, maka penanganan masalah lanjut usia harus menjadi prioritas. Berbagai upaya dapat dilaksanakan untuk mewujudkan masa tua yang sehat, bahagia, berdaya guna dan produktif untuk usia lanjut (Thristyaningsih et al., 2011). Pemerintah telah mencanangkan pelayanan pada lanjut usia melalui beberapa tingkatan sebagai wujud nyata pelayanan sosial dan kesehatan pada kelompok lanjut usia. Pelayanan kesehatan di tingkat masyarakat adalah Posyandu Lansia, pelayanan kesehatan lanjut usia tingkat dasar adalah Puskesmas, dan pelayanan kesehatan tingkat lanjutan adalah Rumah Sakit.

Posyandu lansia merupakan suatu wadah pelayanan kepada lanjut usia yang ada di masyarakat yang menitikberatkan pelayanan kesehatan pada upaya promotif dan preventif (Tuanaya et al., 2018). Selain pelayanan kesehatan, di Posyandu Lansia juga dapat diberikan pelayanan sosial, agama, pendidikan, keterampilan, olah raga, seni budaya serta pelayanan lain yang dibutuhkan para lanjut usia agar kualitas hidup lansia semakin meningkat, dapat beraktifitas dan mengembangkan potensi diri (Komisi Nasional Lanjut Usia, 2010). Akan tetapi dalam pelaksanaanya posyandu belum dikembangkan secara optimal. Posyandu lansia yang telah berjalan saat ini sebagian besar masih menitikberatkan pelayanan kesehatan pada upaya kuratif.
Jumlah lansia di Dusun Sumberbendo dan Dusun Gampang Desa Sumbertebu adalah sebanyak 268 orang. Lansia yang melakukan kunjungan ke Posyandu Lansia terdata sebanyak 26 orang. Jumlah kunjungan lansia tiap bulan mencapai $5-10 \%$ dari total lansia. Hal ini menunjukkan bahwa pemanfaatan pelayanan kesehatan lansia di posyandu masih sangat jauh dari target yang ditetapkan oleh Departemen Kesehatan Republik Indonesia (2010), yaitu mencapai target 70\% dari jumlah lansia.

Rendahnya lansia melakukan kunjungan ke Posyandu Lansia di Desa Sumbertebu dapat disebabkan karena faktor rendahnya kualitas pelayanan kesehatan yang tersedia, karena posyandu lansia lebih pada pelaksanaan upaya kuratif. Sedangkan upaya promotif, preventif dan rehabilitatif belum dilaksanakan dengan baik (Juniardi, 2013). Faktor rendahnya motivasi lansia untuk datang ke posyandu lansia juga menjadi faktor rendahnya kunjungan lansia ke posyandu. Hal ini dapat terjadi karena kurangnya kesadaran lansia tentang pentingnya posyandu lansia. Pemahaman lansia seluruhnya menganggap bahwa posyandu lansia adalah tempat lansia yang sakit untuk berobat, sehingga lansia yang sehat tidak perlu ke Posyandu lansia dan lansia yang sakit yang sudah berobat di pelayanan kesehatan lain tidak perlu lagi datang ke posyandu lansia (Manihuruk \& Nadjib, 2018). Selain itu masyarakat belum memahami sepenuhnya tentang manfaat Posyandu Lansia serta fasilitas yang ada di pelayanan Posyandu Lansia. Sehingga peranan tenaga kesehatan serta kader sangatlah penting dalam melakukan penyuluhan baik kepada lansia, keluarga maupun organisasi-organisasi masyarakat agar kunjungan lansia ke posyandu lansia semakin meningkat (Sulaiman et al., 2018).

Berdasarkan uraian tersebut diatas perlu dilakukan upaya revitalisasi posyandu lansia. Revitalisasi merupakan suatu upaya untuk melakukan perbaikan 
kembali terhadap kegiatan yang telah ada sebelumnya dan dikembangkan sesuai dengan pedoman yang ada. Tujuan dari kegiatan pengabdian kepada masyarakat ini adalah untuk melakukan revitalisasi posyandu lansia di Dusun Sumberbendo dan Dusun Gampang Desa Sumbertebu agar kunjungan lansia dalam pemanfaatan pelayanan kesehatan di Posyandu Lansia lebih meningkat.

\section{METODOLOGI}

Kegiatan pengabdian kepada masyarakat ini dilakukan dengan melibatkan mitra sasaran pada kegiatan revitalisasi posyandu lansia. Kegiatan yang dilakukan dalam program pengabdian kepada masyarakat ini mengadopsi dari hasil penelitian yang sudah dilakukan oleh Mawaddah et al. (2018) dengan menambahkan kegiatan pengembangan posyandu lansia berupa senam lansia dan terapi kelompok. Tahapan kegiatan ini meliputi pelatihan kader lansia, pembuatan media promosi kesehatan untuk kader, sosialisasi pentingnya posyandu lansia ke lansia, keluarga lansia dan masyarakat, kegiatan pendampingan kader lansia dalam pelaksanaan posyandu lansia, serta melaksanakan kegiatan pengembangan posyandu lansia yaitu senam lansia pada bidang olah raga dan terapi kelompok pada bidang pendidikan.

Sebelum kegiatan dilaksanakan, terlebih dahulu dilakukan pengurusan ijin pengabdian kepada masyarakat ini kepada Kepala Desa Sumbertebu. Selanjutnya dilakukaan koordinasi dengan kader lansia untuk kegiatan pelatihan kader lansia. Pelatihan ini ditujukan untuk meningkatkan keterampilan kader dalam melaksanakan posyandu lansia. Pelatihan yang diberikan meliputi : pemberian materi konsep posyandu lansia serta uraian tugas kader lansia, pendidikan kesehatan atau penyuluhan, pemeriksaan kesehatan (Tekanan Darah, Nadi, Respirasi, dan Suhu), penghitungan IMT, pemeriksaan mental emosional, pencatatan kegiatan serta pengisian KMS. Metode kegiatan yang dilakukan adalah ceramah, diskusi, demonstrasi, dan role play. Tahapan kegiatan selanjutnya adalah pembuatan media penyuluhan yang bertujuan untuk memudahkan kader posyandu lansia dalam melaksanakan tugas dalam memberikan pendidikan kesehatan saat pelaksanaan posyandu lansia. Media meliputi leflet pentingnya posyandu lansia serta berbagai masalah kesehatan sering dialami lansia serta pembuatan banner posyandu lansia.

Selanjutnya bersama kader lansia melakukan kunjungan ke rumah lansia untuk melakukan sosialisasi atau penyuluhan pentingnya posyandu lansia langsung kepada lansia dan keluarga. Kegiatan penyuluhan juga dilakukan bersamaan dengan kegiatan dimasyarakat seperti arisan atau pertemuan masyarakat yang lain. sosialisasi dilakukan dengan media leaflet tentang pentingnya datang ke posyandu lansia. Kegiatan kunjungan rumah dilakukan terutama pada lansia yang belum pernah datang keposyandu dan tidak memiliki hambatan fisik datang ke posyandu. Kunjungan dilakukan pada seluruh lansia yang ada di Dusun Sumberbendo dan Dusun Gampang Desa Sumbertebu. Tahap selanjutnya adalah pendampingan pelaksanaan posyandu lansia. Kegiatan ini dilakukan setiap jadwal kegiatan posyandu lansia. Kegiatan yang dilakukan adalah membantu kader melaksanakan kegiatan posyandu yaitu dimeja 1 , meja 2 , meja 3 , meja 4 , serta meja 5. Kegiatan pendampingan program kegiatan pengabdian masyarakat ini dilakukan sebanyak tiga kali pelaksanaan posyandu lansia. Pelaksanaan kegiatan pengembangan dilakukan pada bulan kedua dan ketiga kegiatan, yaitu melaksanakan senam lansia dan terapi kelompok dengan tema terapi dalam kegiatan ini adalah "Peningkatan Kemampuan Adaptasi Lansia". Terapi kelompok Sesi 1 meliputi adaptasi aspek fisik dan sosial, 
dan sesi 2 adaptasi aspek emosional, spiritual dan koqnitif.

\section{HASIL DAN PEMBAHASAN}

Tahapan dalam program kegiatan pengabdian kepada masyarakat ini meliputi pelatihan kader lansia, pembuatan media penyuluhan, sosialisasi melalui kunjungan rumah dan kegiatan masyarakat, kegiatan pendampingan kader lansia dalam pelaksanaan posyandu lansia selama tiga kali kegiatan serta pelaksanaan kegiatan pengembangan. Pelatihan kader lansia diikuti oleh seluruh kader lansia yang ada di Desa Sumbertebu, yaitu berjumlah enam orang dan perawat Desa Sumbertebu sebagai perwakilan Puskesmas. Kepala Desa juga hadir pada hari pertama pelatihan kader ini. Pelatihan ini dilaksanakan di Balai Desa Sumbertebu selama dua hari dengan waktu yang telah disepakati bersama. Selama kegiatan berlangsung terlihat peserta sangat antusias mengikuti kegiatan yang dibuktikan dengan kehadiran peserta pelatihan yang tepat pada jam yang sudah ditentukan. Selain itu selama proses berlangsung peserta juga aktif memberikan pertanyaan kepada narasumber terkait hal-hal yang mereka belum mengetahui dan masalah yang selama ini dialami saat melaksanakan Posyandu Lansia di Dusunnya masing-masing.

Pada hari pertama pelatihan, selain dengan metode ceramah untuk memberikan materi, juga dilakukan demonstrasi serta peserta me-role play-kannya. Pada hari kedua pelatihan, dilakukan diskusi dengan metode Small Group Discussion (SGD) serta penyusunan rencana tindak lanjut. Rencana tindak lanjut yang disepakati adalah melakukan kunjungan rumah lansia untuk memotivasi lansia datang ke posyandu dengan memberikan penjelasan tentang apa itu posyandu lansia, manfaatnya, pentingnya datang secara rutin serta fasilitas yang tersedia diposyandu lansia. Kunjungan rumah dilakukan secara rutin setiap minggu setiap hari jumat jam 9 selama maksimal dua jam. Kunjungan rumah ini dilakukan pada seluruh lansia yang ada di Dusun Sumberbendo dan Dusun Gampang. Hasil kunjungan rumah lansia yang belum pernah datang ke Posyandu dapat dilihat saat pelaksanaan posyandu lansia.

Tahapan selanjutnya adalah melakukan pendampingan dan pembinaan kader dalam pelaksanaan posyandu lansia di semua meja posyandu. Kegiatan pengembangan posyandu lansia senam lansia dan terapi kelompok dilakukan pada bulan kedua dan bulan ketiga kegiatan. Senam lansia dilaksanakan sebelum kegiatan di 5 meja Posyandu dilaksanakan. Sedangkan terapi kelompok dilaksanakan setelah pelaksanaan 5 meja posyandu. Setelah seluruh tahapan dilakukan didapatkan hasil adanya peningkatanjumlah kunjungan lansia ke Posyandu Lansia baik pada posyandu lansia bulan pertama maupun bulan kedua dan ketiga setelah kegiatan pengabdian kepada masyarakat ini. Hasil evaluasi jumlah kunjungan lansia dapat dilihat pada Tabel I.

Tabel I. Hasil Evaluasi Jumlah Kunjungan Lansia ke Posyandu Lansia

\begin{tabular}{ccc}
\hline $\begin{array}{c}\text { Pelaksanaan } \\
\text { Bulan ke- }\end{array}$ & $\begin{array}{c}\text { Jumlah Kunjungan } \\
\text { Lansia (orang) }\end{array}$ & $\begin{array}{c}\text { Persentase } \\
\mathbf{( \% )}\end{array}$ \\
\hline Sebelum & 26 & 10 \\
I & 60 & 22 \\
II & 74 & 28 \\
III & 80 & 30 \\
\hline
\end{tabular}

Berdasarkan Tabel I tersebut menunjukkan bahwa ada peningkatan jumlah kunjungan lansia ke posyandu tiap bulannya secara bertahap. Peningkatan jumlah bertahap ini dapat disebabkan karena dalam kegiatan penyuluhan ataun sosialisasi melalui kunjungan rumah belum dapat dilaksanakan secara maksimal seluruh lansia. Tim pengabdian masyarakat bersama kader melaksanakan kegiatan secara bertahap dan terjadwal setiap minggu sekali setiap hari jumat dengan rata-rata hasil kunjungan 
maksimal 10 rumah lansia. Semakin banyak lansia yang sudah dikunjungi terlihat dari peningkatan jumlah kunjungannya tiap bulan ke Posyandu Lansia. Sehingga diharapkan kader dapat melanjutkan kunjungan rumah sampai seluruh lansia di Desa Sumbertebu sehingga seluruh lansis yang tidak memiliki hambatan secara fisik dapat memanfaatkan fasilitas pelayanan kesehatan di Posyandu Lansia.

Selain faktor sosialisasi melalui kunjungan rumah lansia yang belum maksimal dilakukan, kurang tercapainya target kunjungan lansia ke posyandu lansia juga dapat disebabkan karena faktor internal lansia seperti usia yang lebih banyak datang berusia lansia awal (60-69 tahun), status kesehatan lansia yang kurang baik saat jadwal posyandu lansia, jarak posyandu lansia yang jauh dari rumah, serta jenis kelamin perempuan lebih banyak dari pada laki-laki. Hal ini sesuai dengan hasil studi Mawaddah et al. (2018) bahwa lansia yang aktif datang keposyandu adalah kelompok usia lansia awal, status kesehatan lansia baik, jarak posyandu yang dekat dengan rumah serta jenis kelamin perempuan lebih aktif datang keposyandu.

Peningkatanjumlah kunjungan lansia ini terutama lansia yang aktif datang kePosyandu, disebabkan karena lansia sudah menyadari manfaat serta pentingnya posyandu lansia. Selain itu motivasi lansia untuk datang keposyandu adalah fasilitas yang ada di posyandu saat ini tidak hanya pelayanan kesehatan saja tetapi ada kegiatan lain seperti senam lansia dan terapi kelompok sehingga menambah semangat lansia untuk datang ke Posyandu lansia. Diharapkan kegiatan pengembangan ini dapat tetap berjalan setiap posyandu lansia, serta ada pengembangan kegiatan di bidang lain di Posyandu Lansia. Berdasarkan hasil studi yang dilakukan oleh Putri et al. (2014) menunjukkan bahwa untuk mewujudkan lansia yang sehat jasmani dan rohani serta meningkat kemandirian lansia diperlukan tambahan upaya program lansia di Posyandu Lansia, seperti Program ekonomi, program psikologi, program kesehatan dan program religi. Selain itu dalam pedoman pelaksanaan posyandu lansia oleh Komisi Nasional Lanjut Usia (2010) kegiatan pilihan atau pengembangan yang dapat dilakukan dalam posyandu lansia meliputi bidang olah raga, bidang agama, bidang pendidikan, bidang seni budaya, bidang kesejahteraan dan bidang sosial. Dokumentasi kegiatan Pengabdian yang dilakukan disajikan pada Gambar 1 sampai Gambar 6.

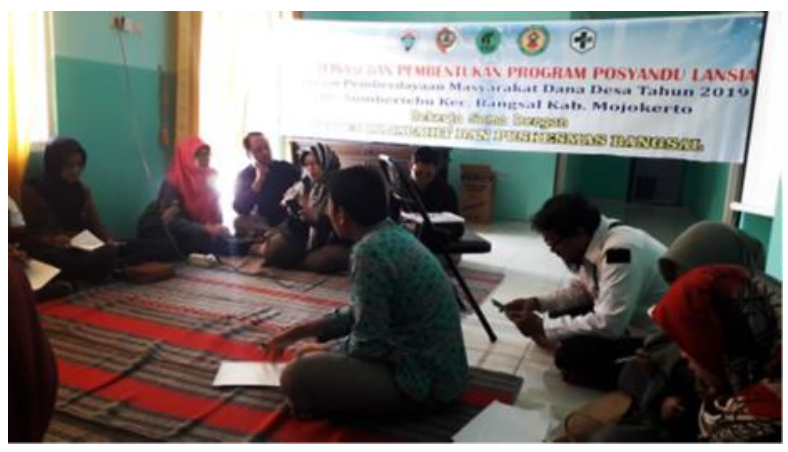

Gambar 1. Pelatihan Kader Lansia

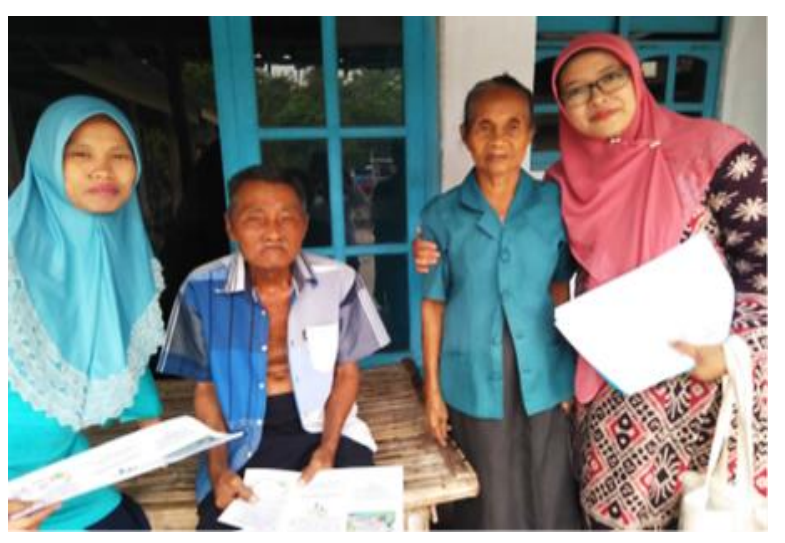

Gambar 2. Sosialisasi ke Rumah Lansia

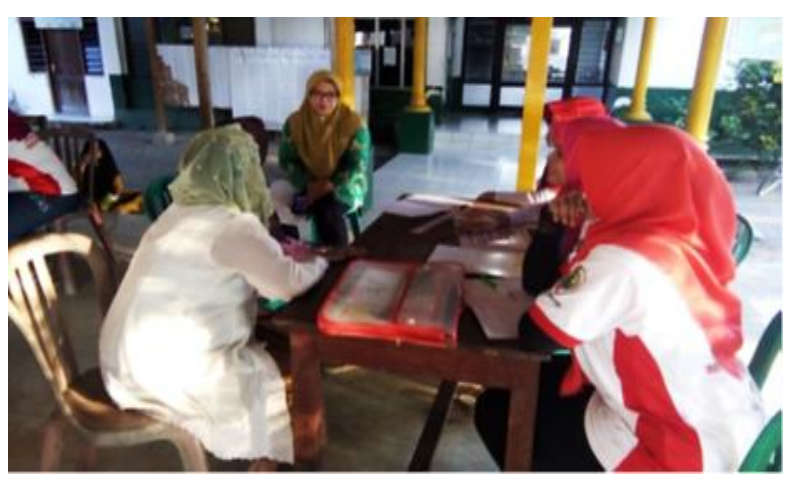

Gambar 3. Pendampingan Kader Lansia 


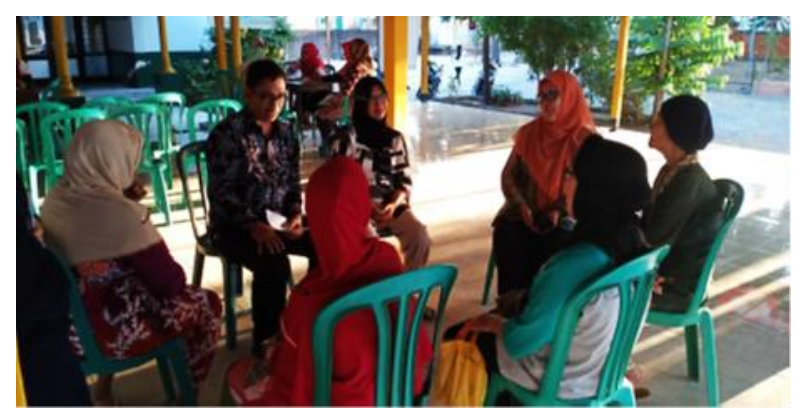

Gambar 4. Terapi kelompok dengan tema "Peningkatan kemampuan Adaptasi Lansia" sebagai bentuk pelayanan pengembangan dari posyandu lansia

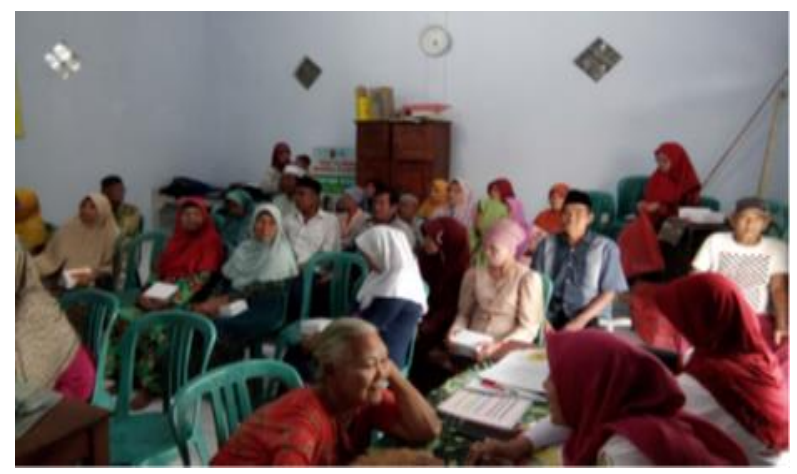

Gambar 5. Pelaksanaan Posyandu Lansia

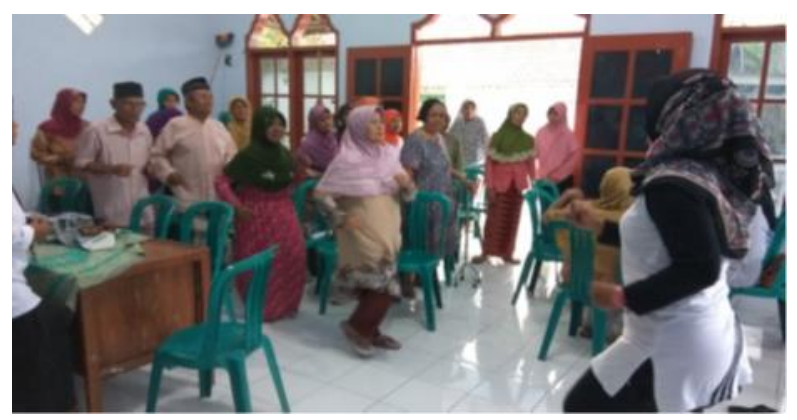

Gambar 6. Senam Lansia sebagai bentuk pelayanan pengembangan dari kegiatan posyandu lansia

\section{KESIMPULAN}

Program kegiatan pengabdian kepada masyarakat ini berjalan dengan lancar serta sangat bermanfaat sebagai pedoman bagi pembentukan posyandu lansia di Dusun lain di Desa Sumbertebu. Para kader lansia sangat antusias dan memahami fungsi dan tugasnya sebagai kader. Pemahanan dan keterampilan kader dalam pelaksanaan posyandu lansia mejadi meningkat.
Program pengabdian kepada masyarakat yang dilaksanakan selama empat bulan ini sejak pengurusan ijin sampai evaluasi pelaksanaan posyandu lansia selama tiga kali, mampu meningkatkan jumlah kunjungan lansia ke posyandu dengan pencapaian 30\% dari jumlah lansia. hasil pencapaian ini akan dapat bertambah jika kader dapat melanjutkan kegiatan kunjungan rumah seluruh lansia. Selain itu sosialisasi tentang jadwal dan pentingnya posyandu hendaknya selalu disampaikan bersamaan dengan kegiatan dimasyarakat. Meningkatkan sasaran peserta posyandu lansia mulai dari usia pra lansia akan dapat meningkatkan kualitas hidup lansia. Mempertahankan kegiatan pengembangan yang sudah ada dan menambah kegiatan pengembangan di posyandu lansia dapat meningkatkan motivasi lansia datang ke posyandu.

\section{UCAPAN TERIMA KASIH}

Terima kasih kami ucapkan kepada semua pihak yang mendukung program ini, yaitu LPPMSTIKes Majapahit, Desa Sumbertebu sebagai mitra pelaksanaan program ini, seluruh kader lansia yang sangat antusias dengan tugasnya serta seluruh sivitas akademika yang telah membantu pelaksanaan kegiatan Pengabdian.

\section{REFERENSI}

Braveman, P., Gottlieb, L. 2014. The Social Determinants of Health: It's Time to Consider the Causes of the Causes. Public Health Reports. 129(Suppl 2):19-31.

https://dx.doi.org/10.1177/00333549141291S 206

Departemen Kesehatan Republik Indonesia. 2010. Pedoman Pembinaan Kesahatan Usia Lanjut Bagi Petugas Kesehatan. Jakarta: Direktorat Kesehatan Keluarga. 
Heryanah. 2015. Ageing Population Dan Bonus Demografi Kedua Di Indonesia. Populasi. 23(2):1-16. https://doi.org/10.22146/jp.15692

Juniardi, F. 2013. Faktor-Faktor Yang Mempengaruhi Rendahnya Kunjungan Lansia Ke Posyandu Lansia Di Puskesmas Batang Beruh Kecamatan Sidikalang Kabupaten Dairi. Welfare State. 2(1):1-7.

Komisi Nasional Lanjut Usia. 2010. Pedoman Pelaksanaan Posyandu Lanjut Usia. Jakarta: PPLU.

Manihuruk, M., Nadjib, M. 2018. Faktor-faktor yang Berhubungan dengan Kunjungan Lansia ke Posbindu Lansia di Wilayah Kerja Puskesmas Kelurahan Bintara Kota Bekasi Tahun 2017. Jurnal Kebijakan Kesehatan Indonesia: JKKI. 7(4):158-167.

https://doi.org/10.22146/jkki.26409

Mawaddah, N., Syurandhari, D.H., Basahi, H. 2018. Optimalisasi Posyandu Lansia Sebagai Upaya Peningkatan Partisipasi Dan Kualitas Hidup Lansia. Medica Majapahit. 10(2):100-110.

Partini, S. 2011. Psikologi Usia Lanjut. Yogyakarta: Gadjah Mada University Press.

Putri, D.K., Amalia, R.N., Widyaningsih, E., Oktoriandini, C., Sawitri, P.A. 2014. Opa Oma (Optimalisasi Posyandu Lansia Untuk Mendukung Kemandirian Lansia). Community Service Report. Bogor: Institut Pertanian Bogor.

Sulaiman, Sutandra, L., Vera, Y., Anggriani. 2018. Pendampingan Kader Posyandu Lansia Di Suka Raya. Journal of Dedicators Community. 2(2):116-122.

https:/ /doi.org/10.34001/jdc.v2i2.712

Thristyaningsih, S., Probosuseno, P., Astuti, H. 2011. Senam bugar lansia berpengaruh terhadap daya tahan jantung paru, status gizi, dan tekanan darah. Jurnal Gizi Klinik Indonesia. 8(1):14-22.

https://doi.org/10.22146/ijcn.17726

Tuanaya, F.H.A., Wahyuni, D., Zulkarnain, E. 2018. Upaya Promotif Petugas Kesehatan dalam Pelaksanaan Posyandu Lansia di Puskesmas Mangli Kabupaten Jember. Multidisciplinary Journal. 1(1):11-16. https:/ /doi.org/10.19184/multijournal.v1i1.8 591 